\title{
Preface: Jellyfish blooms: interactions with humans and fisheries
}

\author{
Hermes Mianzan · Jennifer E. Purcell • \\ Jessica R. Frost
}

Published online: 15 March 2012

(C) Springer Science+Business Media B.V. 2012

There is a general impression that jellyfish and other gelatinous organisms are increasing in number. Media, $\mathrm{TV}$, and newspapers contribute to this impression. So are increases in jelly populations real, or is this phenomenon just a biased perception? Answering this question is a difficult task because jelly populations normally fluctuate enormously, being everywhere some years, and impossible to find in others. It is also true that occasional swarms of great density have a notorious effect on many human economic activities such as tourism, fisheries, and various coastal industries.

Ten years ago the first Jellyfish bloom meeting was envisioned. Held at Gulf Shores, Alabama in January 2000 , it was a response to the need to consider the

Guest editors: J. E. Purcell, H. Mianzan \& J. R. Frost / Jellyfish Blooms: Interactions with Humans and Fisheries

Electronic supplementary material The online version of this article (doi:10.1007/s10750-012-1050-z) contains supplementary material, which is available to authorized users.

\section{H. Mianzan}

CONICET-Instituto Nacional de Investigación y,

Desarrollo Pesquero (INIDEP), Paseo Victoria Ocampo,

n_1, B7602HSA Mar del Plata, Argentina

e-mail: hermes@inidep.edu.ar

\section{J. E. Purcell (ه)}

Western Washington University, Shannon Point Marine Center, 1900 Shannon Point Road, Anacortes, WA 98221, USA

e-mail: purcelj3@wwu.edu ecological as well as societal aspects of jellyfish blooms. The main objective was to come together and find a unified voice that would direct new fields of research on the subject. The second International Jellyfish Blooms Symposium was held on the Gold Coast, Queensland, Australia in June 2007, and the general message was to examine the problem on a wider scale, encouraging people to consider the use of fisheries as well as molecular techniques for jellyfish research. And recently, special sessions on gelatinous plankton can be found in other general meetings like the Nice ASLO meeting in January 2009. In each of the three cases mentioned, about 60 talks and posters were presented and a special volume published.

What is our ultimate goal? To understand the dynamics and impacts of jellyfish blooms at a global scale. The Third Symposium, organized by Hermes Mianzan, Gabriel Genzano, Agustin Schiariti and Marcelo Acha, held 13-16 July 2010 in Mar del Plata, Argentina, reached us at the right time. We are facing clear examples that some jellyfish species are increasing

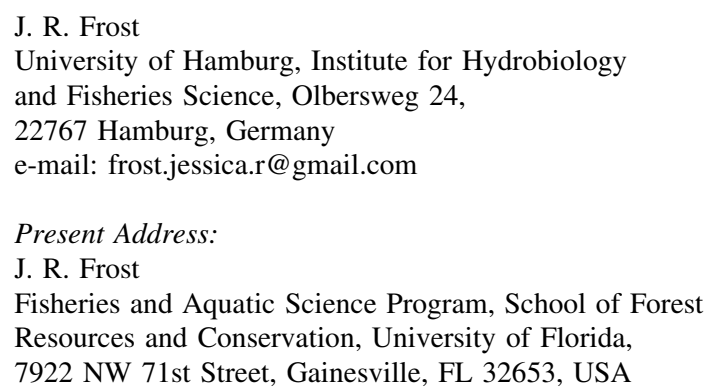


their frequency of occurrence, expanding their geographical distributional range, being introduced, with sometimes devastating consequences on human enterprises. Mnemiopsis leidyi, the ctenophore that gained a "bad reputation" by invading the Black Sea in the 1980s is continuously expanding its distributional range and every year it is found in new localities. Nemopilema nomurai, a giant Asian scyphozoan, undertakes interannual population explosions generating severe damage to the Japanese fishing industry in the last 10 years. Even nuclear power stations occasionally need to stop their activities due to jellies that have clogged their refrigerating water intakes. And more and more examples are continuously being reported.

Within this third meeting, attention was placed on fish-jellyfish interactions, and fisheries. More than a 100 talks and posters have been presented by the 98 delegates from 31 countries. Dr. Daniel Pauly offered the Keynote Address on "Changes of Jellyfish Abundance: Testing Hypotheses at the Large Marine Ecosystem Scale." Dr. Jenny Purcell run a special session on "Causes and consequences of Jellyfish Outbreaks and Aggregations" with invited speaker,
Dr. Shin-ichi Uye, Dr. Rick Brodeur spoke in the second special session, "Interactions Between Jellyfish and Marine Fish and Fisheries: Insights into Ecosystem Functioning". A variety of topics were included in the General Session.

The papers presented in this volume are a subset of the $100+$ talks and posters presented at the meeting (Supplement 1). They provide a good representation of the diversity of issues discussed and hopefully will stimulate researchers worldwide to continue research into how and why jellyfish blooms occur.

H. Mianzan (conference organizer and guest editor) J. E. Purcell (guest editor)

J. R. Frost (guest editor)

Acknowledgments The guest editors and conference organisers wish to thank the sponsors of the symposium, specifically INIDEP, CONICET, Agencia, IAI, Mar del Plata National University, and AACIMA. The guest editors are also indebted to the numerous referees for their detailed and insightful reviews of manuscripts and, of course, to the contributing authors who stoically endured the numerous queries and requests of the guest editors. 